\title{
Uma história da Abordagem Centrada na Pessoa no Brasil
}

\section{A history of the Person Centered Approach in Brazil}

\author{
Alexandre Trzan-Ávila* \\ Universidade do Estado do Rio de Janeiro - UERJ, Rio de Janeiro, Rio de Janeiro, \\ Brasil
}

\section{Ana Maria Jacó-Vilela**}

Universidade do Estado do Rio de Janeiro, Rio de Janeiro, Rio de Janeiro, Brasil

\begin{abstract}
RESUMO
O objetivo deste trabalho é construir um relato histórico da emergência da Abordagem Centrada na Pessoa no Brasil (ACP), visando responder às seguintes perguntas: como esta abordagem chega ao Brasil; com quem chega; como se desenvolve; quais influências de âmbito nacional esta abordagem recebe. Estas questões se fazem pertinentes pela constatação que a ACP entra no Brasil em uma época atravessada por movimentos libertários, como a contracultura, movimentos de minoria, antipsiquiatria e as batalhas pela democracia no Brasil. A ACP é uma das primeiras vertentes da Psicologia Humanista e deve sua sistematização ao psicólogo norteamericano Carl Rogers, que aponta para uma perspectiva de homem e das relações humanas e valoriza a potência de desenvolvimento do ser humano. O presente trabalho utiliza o método historiográfico, que consiste em um processo de reconstrução da história.
\end{abstract}

Palavras-chave: História da Psicologia, Abordagem Centrada na Pessoa, Historiografia.

\begin{abstract}
The objective of this study is to develop a historical account of the emergence of Person-Centered Approach in Brazil (PCA), to answer the following questions: how this approach arrives at Brazil, with whom it comes, how does it develop and which nationwide influences does this approach receive. These issues become relevant due to the fact that the PCA enters Brazil at a time crossed by liberation movements, such as the counterculture, minority movements, anti-psychiatry and the struggles for democracy in Brazil. The PCA, first currents of the Humanist Psychology, owes its systematization to the American psychologist Carl Rogers, who points to a view of man and of human relations, who values the power of human development. This paper uses the historiographical method, which consists in a process of reconstructing the history.

Keywords: History of Psychology, Person Centered Approach, Historiography.
\end{abstract}


Este trabalho pretende estabelecer um quadro histórico do período em que ocorreu a emergência e o desenvolvimento da Abordagem Centrada na Pessoa no Brasil. Como afirma Rodrigues (2004), "todo saber seria ideológico, por refletir a infra-estrutura econômica da sociedade". E não pretende ser uma análise em termos de influências e muito menos quer explicar um movimento a partir de outros autores, antecessores ou contemporâneos, para assinalar originalidades ou celebrar precursores.

Um dos motivos que me impulsionaram na construção deste projeto foi a minha curiosidade frente à vida, em seu aspecto relacionado à minha formação profissional. Ressalto que ao longo de minha formação como psicólogo, esta não encerrada pela conclusão da graduação, continuamente fui apresentado a teorias, modelos de homem, reflexões sócio-culturais, e de todo este percurso optei por alguns caminhos e nestes me aprofundei. Por exemplo, a minha formação na Abordagem Centrada na Pessoa, uma das vertentes mais importantes da Psicologia Humanista, na qual passei a atuar clinicamente, sem, porém, deixar de questionar que influências determinaram o modelo de homem, dotado de potencialidades para o crescimento, livre-arbítrio, auto-determinação e digno de confiança, e as relações interpessoais preconizadas por esta teoria.

É sabido que esta abordagem teve seu crescimento principalmente entre as décadas de 1950 e 1970, época fortemente marcada pela Guerra Fria, Revoluções Chinesa e Cubana, Guerra do Vietnã e, no Brasil, pelo Golpe Militar de 64 e o AI5, além de movimentos como o da contracultura, oriundo do solo norte-americano, entre muitos outros movimentos, como os movimentos feminista e Gay, ambos oriundos também dos Estados Unidos. Pergunto, então: esta teoria faria sentido somente no contexto sócio-histórico onde se desenvolveu? O solo americano e suas idéias pragmáticas deram a "cara" que a ACP tem no Brasil? Ou a ACP no Brasil é negra, é índia, é branca, é mista?

Jacó-Vilela (2004) aponta para a necessidade de articular as condições brasileiras de momentos históricos pontuais, com 0 surgimento e crescimento de determinadas teorias e abordagens psicológicas. Ela afirma a "impossibilidade de se pensar os saberes e práticas "psi" de forma isolada e autônoma, independentemente das condições em que emerge, estabiliza-se e floresce". (p. 94)

O principal e quase único trabalho sobre a história da ACP é uma pesquisa realizada por Márcia Tassinari, sócia fundadora do Centro de Psicologia da Pessoa, instituição criada há mais de 35 anos no Rio de Janeiro. Realizada entre os anos de 1990 e 1997, nesta pesquisa Tassinari já apontava para a escassa produção teórica sobre o contexto sócio-político da ACP no Brasil: "Vale ressaltar que poucos autores destacam questões relativas ao contexto sócio-político- 
cultural tão diferente das raízes do pensamento de Rogers" (2010, p. 48).

Conhecer a história da teoria que embasa o próprio trabalho possibilita saber de onde se está falando, permite avaliar o quanto os atravessamentos políticos e sociais que acompanharam a criação e evolução deste pensar o homem e suas relações influenciaram diretamente o modelo de homem, a visão de mundo e sociedade que constituem este saber. Portanto compreender como uma teoria se constitui e seus pressupostos permite avaliar a construção e a própria aplicação de uma teoria, buscando compreender a quem serve e o modo como a mesma pode ser aplicada em contextos determinados.

Os questionamentos apontados anteriormente são de fundamental importância dado que: diversas graduações, pós-graduações e especializações oferecem disciplinas, e fomentam a elaboração de monografias, dissertações, teses e artigos científicos e a existência de instituições formadoras, conforme pode ser visto no sítio da Associação Paulista da Abordagem Centrada na Pessoa (<http//:www.apacp.org.br>).

A partir do quadro acima exposto, entender-se que registrar a história da ACP no Brasil é uma tarefa que se justifica dada a sua acolhida e o grande contingente de profissionais que atuam neste referencial teórico.

Quanto à definição do método da pesquisa, conforme orienta Sá (2007), o principal objetivo em uma pesquisa histórica é fazer emergir a extrema riqueza e complexidade da memória como fenômeno psicossocial. Portanto, entre os métodos possíveis de serem utilizados nesta pesquisa será adotada a metodologia da historiografia, por se tratar de um processo de reconstrução e reconstituição da história.

O método historiográfico consiste em um processo de reconstrução da história. Neste processo o pesquisador tem um papel fundamental, por que além de buscar informações, é ele quem irá narrar o fato histórico, sendo assim produtor de conhecimento ao criar e estabelecer significados. Este trabalho se insere em uma proposta da historiografia da psicologia que, segundo Brozek e Massimi (1998), "começa com o relato de algum fato, contextualizado em seu contexto temporal e espacial. Trata-se, porém de um relato que não apenas narra o fato, mas também busca explicá-lo".

A reconstrução da memória histórica pretendida a ser concluída na dissertação de mestrado comporta duas modalidades, a saber: "memória histórica documental" e "memória social oral". A primeira será a pesquisa e análise de documentos e a segunda será o relato oral instrumentalizado por entrevistas. Pretende-se que em um primeiro momento, seja realizada a investigação bibliográfica de fontes primárias como atas, matérias de jornais etc, bem como de comentadores e teses, livros, artigos e outros documentos. 
A pesquisa das condições culturais e econômico-sociais do Brasil na época em questão será feita através da obra de estudiosos da história do Brasil, iniciando-se na década de 1960, momento em que atravessávamos uma imensa crise econômica com inflação muito alta. Neste cenário rompe o golpe militar de 1964, justificado como prevenção a uma ameaça comunista (ANSARA, 2008). A partir daí, o que se presenciou foram os setores populares e democráticos do país pagando um preço muito elevado pela resistência oferecida aos Militares.

Vale lembrar que no cenário internacional cresce o horror norteamericano ao comunismo, especialmente em razão da Revolução Cubana (1959), à Guerra do Vietnã (1959 a 1975) e pela intensificação da Guerra Fria, período que compreendeu o final da Segunda Guerra Mundial (1945) e o fim da União Soviética (1991) juntamente com a queda do Muro de Berlim na Alemanha, conflito que envolvia os Estados Unidos e a União Soviética e suas zonas de influência, separando o mundo em dois blocos (BLAINEY, 2009).

É também neste período que se desenvolve, em solo americano, a contracultura, um movimento que tem seu auge na década de 1960, quando teve lugar uma forma de mobilização e contestação social, onde jovens com um espírito mais libertário, afinados com uma cultura alternativa ou hippie (que se opunha radicalmente ao trabalho, ao patriotismo, ao nacionalismo e à ascensão social), focada principalmente na transformação da sociedade defendem uma mudança de atitude, protestando contra a Guerra do Vietnã, o machismo, a discriminação racial, visando a construção de novos canais de expressão para o indivíduo. A contracultura questionava valores centrais da cultura ocidental. Posteriormente, a contracultura desenvolveu-se na Europa e América Latina. No Brasil fez-se presente principalmente nos anos 1970 e início dos 1980, conforme aponta Almeida (2009).

Emerge também nos EUA a Psicologia Humanista e um psicólogo brasileiro que contribuiu para expansão desta psicologia no Brasil, Rogério Buys (2010), esclarece: "o termo "humanismo" surgiu no Renascimento no final do século XIV e denominava tanto um aspecto literário, os escritores clássicos, quanto um viés filosófico, preocupando-se com o valor do homem e a tentativa de compreendêlo em seu mundo" (p. 339).

A Psicologia Humanista, que não é uma filosofia nem mesmo uma teoria, é mais bem explicada como um movimento inicialmente organizado pelo psicólogo norte-americano Abraham Maslow na década de 1950, que organizou uma lista com nomes e endereços de psicólogos que, em sua prática diária, encontravam-se descontentes com os modelos de homem e práticas psicoterápicas predominantes na época. Após diversos encontros e trocas de experiências entre estes psicólogos e os demais interessados, foi fundada em 1961 a 
Revista de Psicologia Humanista. Com seu sucesso, criou-se a Associação Americana de Psicologia Humanista, em 1963. Hoje a psicologia humanista se mostra uma força firmemente estabelecida e reconhecida no panorama da psicologia mundial.

A Psicologia Humanista se caracteriza por ser uma Psicologia do homem como um todo, com o seu inconsciente, consciente, condicionamentos e todo o resto, mas levando em conta acima de tudo as características do homem que o distinguem dos animais e das máquinas (BOAINAIN, 1998). É uma Psicologia atenta ao crescimento e à promoção da Saúde, em detrimento dos modelos deterministas e causais. Ela considera a importância das influências provenientes do ambiente, do passado ou do inconsciente, porém leva em conta o livre-arbítrio, a responsabilidade e a intencionalidade como características intrínsecas à condição humana (TRZAN-ÁVILA, 2007).

Dentro deste movimento destaca-se o psicólogo norte-americano Carl Rogers que foi um dos principais colaboradores desta nova força em Psicologia, criando uma de suas ramificações, atualmente denominada de Abordagem Centrada na Pessoa. Esta caracteriza a última fase de seus trabalhos e sustenta uma determinada perspectiva de homem e das relações humanas. Esta teoria e sua evolução ocorreram a partir da própria prática de psicoterapia realizada por Rogers, ou seja, é uma teoria que se adequou ao homem e não o homem a esta (ROGERS, 1983). Partindo da psicoterapia, Rogers e seus colaboradores ampliaram a atuação da ACP para a educação, a saúde hospitalar, as organizações etc.

A proposta inicial de Rogers foi estabelecer as condições necessárias e suficientes para que se produzam mudanças terapêuticas da personalidade do cliente, isto é, definir as condições cuja presença favoreça o processo de mudança, para que o homem possa viver de maneira mais integrada, com menos conflitos internos, seguindo em direção a comportamentos mais maduros. Segundo Rogers, as três atitudes do terapeuta em relação ao seu cliente são: congruência, consideração positiva incondicional e empatia (ROGERS, 1988).

Partindo inicialmente das informações levantadas por Tassinari (2010) sobre a emergência e constituição da ACP no Brasil, apresentam-se os seguintes indicativos, dentre eles que a brasileira Mariana Alvim, talvez tenha sido a primeira pessoa a trazer as idéias de Carl Rogers para o Brasil, ela o conheceu em 1945, em Chicago, quando foi estudar instituições nos EUA que trabalhavam com menores delinqüentes. Aprendeu o que na época denominava-se "entrevista não-diretiva". Em 1947, Mariana foi chamada para organizar o Instituto de Seleção e Orientação Profissional (ISOP) no Rio de Janeiro, quando passou a usar efetivamente a "técnica nãodiretiva".

Uma das primeiras ações de institucionalização da Abordagem no Brasil foi à criação do Serviço de Aconselhamento Psicológico (SAP) 
da Universidade do Estado de São Paulo (USP), na década de 1960, sob a coordenação de Oswaldo de Barros Santos, com o apoio de sua ex-aluna Rachel Rosenberg. Era um serviço com base teórica ancorada no pensamento rogeriano. Já na década de 70 foi criado o Centro de Desenvolvimento da Pessoa no Instituto Sedes Sapientiae, por iniciativa também da psicóloga Rachel Rosenberg.

Em 1963 a ACP se fez presente no Primeiro Curso de Psicologia da Universidade Federal de Minas Gerais (UFMG), que contemplou seus alunos com seminários e os professores com treinamento sobre a Teoria Centrada no Cliente. Vale ressaltar que o primeiro Grupo de Formação de Psicoterapeutas nesta abordagem foi coordenado por Antonio Luiz Costa, no final da década de 60 também em MG. Por sua vez no Rio de Janeiro é fundado o Centro de Psicologia da Pessoa em 1975, este um dos núcleos mais antigos do Brasil que continua em atividade através de cursos de formação, atendimento psicoterápico e organização de eventos.

Portanto espero concluir esta pesquisa apontando para os principais aspectos do contexto histórico-social brasileiro onde ocorreu a emergência e desenvolvimento da Abordagem Centrada na Pessoa. Finalmente, espero que este trabalho sirva de modelo para uma reflexão voltada aos profissionais da área, os quais venham adotar este referencial teórico.

\section{Referências}

ALMEIDA, M. I. M.; NAVES, S. C. "Por que não?" - rupturas e continuidades da contracultura. São Paulo, Ed. 7 letras. 2009.

ANSARA, S. Memória Política, Repressão e Ditadura no Brasil. Curitiba, Juruá Editora, 2008.

ASSOCIAÇÃO PAULISTA DA ACP. Disponível em: <www.apacp.com.br>. Acesso em: 26 set. 2010.

BLAINEY, G. Uma breve história do mundo. São Paulo, Editora Fundamento, 2009.

BOAINAIN, E. Tornar-se transpessoal. São Paulo, Summus Editorial, 1998 .

BROZEK, J; MASSIMI, M. (Orgs.). Historiografia da piscologia moderna. São Paulo, Edições Loyola/Unimarco. 1998.

BUYS, R. C. A psicologia humanista. In: JACÓ-VILELA, A. M.; FERREIRA, A. A. L.; PORTUGAL, F. T. (Orgs.). História da psicologia: Rumos e Percussos. Rio de Janeiro, Nau Editora. 2010, p. 339-348.

JACÓ-VILELA, A. M. Análise Inicial da Produção escrita em Psicologia no Brasil. In: JACÓ-VILELA, A. M.; MANCEBO, D. (Orgs.). Psicologia social: abordagens sócio-históricas e desafios contemporâneos. Rio de Janeiro, EdUERJ. 2004, p.93-109. 
RODRIGUES, H. de B. C. Sobre as Histórias das Práticas Grupais: explorações quanto a um intrincado problema. In: JACÓ-VILELA, A. M; MANCEBO, D. (Orgs.). Psicologia social: abordagens sóciohistóricas e desafios contemporâneos. Rio de Janeiro, EdUERJ. 2004, p.113-168.

ROGERS, C. R. Um jeito de ser. São Paulo, E.P.U., 1983.

. Tornar-se pessoa. São Paulo, Martins Fontes, 1988.

SÁ, C. P. Psicologia Social da Memória: sobre memórias históricas e memórias geracionais. In: JACÓ-VILELA, A. M.; SATO, L. (Orgs.). Diálogos em psicologia social. Porto Alegre, Editora Evangraf. 2007, p. 53-61.

TRZAN-ÁVILA, A. A Abordagem Centrada na Pessoa e o Processo Terapêutico. 2007. 49 f.Monografia (Graduação em Psicologia) - Universidade Veiga de Almeida, Rio de Janeiro.

CARRENHO, E; TASSINARI, M; PINTO, M. A. DA S.Praticando a abordagem centrada na pessoa. São Paulo, Carrenho Editorial. 2010.

\section{Endereço para correspondência \\ Alexandre Trzan-Ávila \\ CLIO-PSYCHÉ - Programa de Estudos e Pesquisas em História da Psicologia Universidade do Estado do Rio de Janeiro - UERJ. Rua São Francsico Xavier, 524, $10^{\circ}$ andar, bloco $\mathrm{F}$, sala 10120. \\ Endereço eletrônico: atrzan@gmail.com}

Ana Maria Jacó-Vilela

CLIO-PSYCHÉ - Programa de Estudos e Pesquisas em História da Psicologia Universidade do Estado do Rio de Janeiro - UERJ. Rua São Francsico Xavier, 524, $10^{\circ}$ andar, bloco F, sala 10120. Tel: (0xx21) 2334-0830

Endereço eletrônico: amjaco@uol.com.br

Recebido em: $11 / 11 / 2011$

Reformulado em: 02/07/2012

Aceito para publicação em: 02/07/2012

Acompanhamento do processo editorial: Ana Maria Lopez Calvo de Feijoo

\footnotetext{
Notas

* Mestrando do Programa de Pós-Graduação em Psicologia Social (PPGPS) da Universidade do Estado do Rio de Janeiro - UERJ, Rio de Janeiro - Brasil. Graduado em Psicologia pela Universidade Veiga de Almeida.

**Professora Associada da Universidade do Estado do Rio de Janeiro - UERJ, Rio de Janeiro - Brasil.
} 